\title{
ASSOCIACÃO ENTRE ACIDENTES VASCULARES ENCEFÁLICOS E DOENÇA DE CHAGAS
}

\author{
Edison Reis Lopes, Jaime Olavo Marquez, Bertolino da Costa Neto, \\ Ayres Alexandre Carlos Menezes e Edmundo Chapadeiro
}

\begin{abstract}
Foi pesquisada a freqüência de acidentes vasculares encefálicos (AVE), isquêmicos e hemorrágicos, em chagásicos crônicos e em não chagásicos, maiores de 15 anos de idade, necropsiados em Uberaba, de 1979 a 1988, optando-se por estudo emparelhado por sexo e idade em 208 pares. Em 41 (19,7\%) dos chagásicos e em 55 (26,4\%) dos nāo chagásicos foram diagnosticados AVE, diferença não significante ao nivel de $5 \%$. Dos chagásicos $12(75 \%)$ tiveram infarto e 4 (25\%) hemorragia encefálica; dos não chagásicos 5 (31,3\%) tiveram infarto e 11 $(68,7 \%)$ hemorragia. As diferenças são significantes ao nível de $5 \%$. Os resultados demonstram menor freqüência de $A V E$ hemorrágico em chagásicos que em não chagásicos e comprovam alta freqüência de AVE isqüêmico na doença de Chagas humana.
\end{abstract}

Palavras-chaves: Doença de Chagas. Acidente vascular encefálico. Acidente vascular cerebral. Hemorragia encefálica. Infarto cerebral.

Nas áreas endêmicas da doença de Chagas (DC) parecem relativamente freqüentes os acidentes vasculares encefálicos (AVE) de natureza isquèmica1 911 13. Entretanto, ao que nos consta, não há estudos sistematizados sobre os AVE hemorrágicos, o que parece de interesse tendo em vista dados da literatura (ver revisão bibliográfica em Guariento ${ }^{5}$ ) que indicam ser a hipertensão arterial sistêmica, principal causa da hemorragia encefálica ${ }^{4}{ }^{10}$, menos freqüente nos chagásicos.

Com o objetivo de contribuir para o melhor conhecimento desses distúrbios circulatórios na DC, pesquisamos, através de estudo pareado por sexo e idade, a freqüência de AVE em autópsias realizadas no Triângulo Mineiro, onde cerca de $40 \%$ dos necropsiados apresentam infeç̧ão chagásica.

\section{MATERIAL E MÉTODOS}

Consta de 270 chagásicos falecidos por insuficiência cardíaca, subitamente, de modo violento (homicidio, acidente, suicídio) ou por doenças intercorrentes e de 473 não chagásicos. Todas as necrópsias foram realizadas em maiores de 15 anos de idade, no

Trabalho do Curso de Pós-Graduação em Patologia Humana e do Departamento de Neurologia da Faculdade de Medicina do Triângulo Mineiro, Uberaba, MG, Brasil.

Endereço para correspondência: Dr. Edison Reis Lopes, Departamento de Patologia, Deontologia Médica e Medicina Legal/FMTM. Pça. Manoel Terra s/n. 38010 Uberaba, MG, Brasil.

Recebido para publicação em 08/01/91.
Hospital Escola da Faculdade de Medicina do Triângulo Mineiro e no Posto Médico Legal de Uberaba, entre 1979 e 1988.

O diagnóstico de DC foi baseado nos achados sorológicos e/ou morfológicos ${ }^{6}$ e o de AVE (isquêmico ou hemorrágico) segundo os critérios de Schoene ${ }^{14}$.

Com finalidade de contornar, pelo menos parcialmente, a ação de variaveis efeitos modificadoras e/ou tendenciosidades, devido ao caráter de casuística hospitalar, optou-se por estudo emparelhado por sexo e idade. Para isto a cada chagásico selecionou-se um não chagásico, falecido em época próxima, do mesmo sexo e de idade similar (variação máxima de 5 anos para mais ou para menos), optando-se sempre pela igualdade etária. Com esta metodologia foi possivel pesquisar-se a freqüência de AVE, hemorrágico ou isquêmico, em 208 pares; a distribuição destes, por sexo e comportamento etário é mostrada na Tabela 1.

A análise estatística para as diferenças entre proporções do estudo emparelhado foi feita pelo teste de $\mathrm{McNemar}^{2}$, considerando-se o nivel de significância de $5 \%$.

\section{RESULTADOS}

As Tabelas 2 e 3 sumarizam as freqüências obtidas a partir da metodologia de seleção emparelhada de chagásicos e não chagásicos. A Tabela 2 mostra que $41(19,7 \%)$ dos chagásicos e $55(26,4 \%)$ dos não chagásicos apresentaram AVE isquêmico ou hemorrágico e esta diferença não é signifícativa ao nível de $5 \%$ (teste de McNemar $=2,6406 \mathrm{p}=0,1042$ ).

A Tabela 3 mostra a distribuição dos tipos de acidentes vasculares nos 16 pares (indicados na 
Lopes ER, Marquez JO, Costa Neto B, Menezes AAC, Chapadeiro E. Associacão entre acidentes vasculares encefálicos e doença de Chagas. Revista da Sociedade Brasileira de Medicina Tropical 24: 101-104, abr-jun, 1991

Tabela 1 - Distribuição de 208 pares de chagásicos e de não chagásicos, de acordo com a idade e sexo.

\begin{tabular}{|c|c|c|c|c|}
\hline \multirow{2}{*}{ Carac- } & \multicolumn{2}{|c|}{ chagásicos } & \multicolumn{2}{|c|}{ não chagásicos } \\
\hline & homens & mulheres & homens & mulheres \\
\hline No de casos & 156 & 52 & 156 & 52 \\
\hline $\begin{array}{l}\text { idade (anos) } \\
\text { amplitude }\end{array}$ & $15-83$ & $22-85$ & $15-88$ & $23-85$ \\
\hline $\begin{array}{l}\text { média } \pm \text { desvio } \\
\text { padrão }\end{array}$ & $52.31 \pm 14.25$ & $50.88 \pm 14.38$ & $52.00 \pm 14.27$ & $51.15 \pm 14.38$ \\
\hline
\end{tabular}

Tabela 2 - Distribuição dos pares de chagásicos e não chagásicos segundo a presença de acidente vascular encefälico.

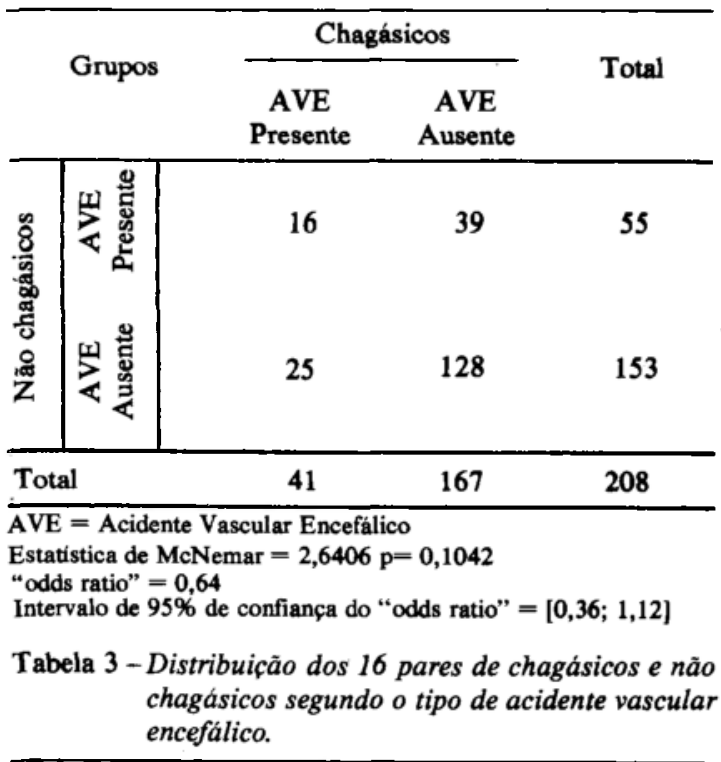

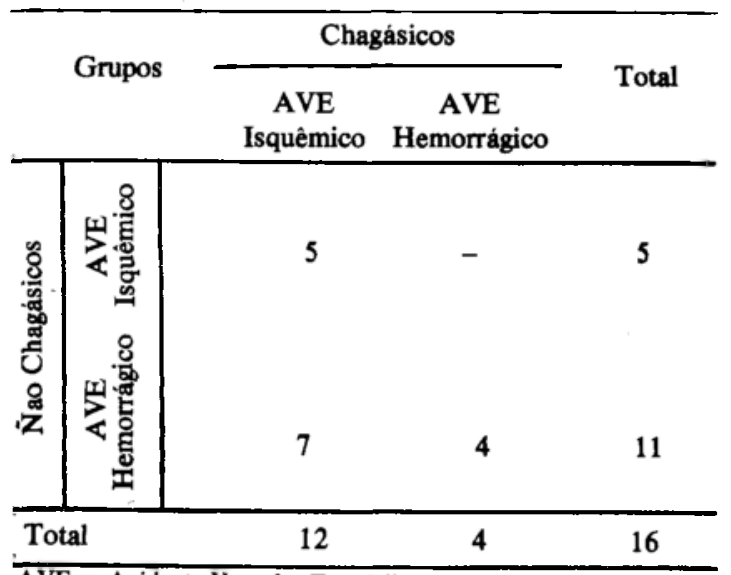

AVE $=$ Acidente Vascular Encefálico

$\mathbf{P}=0,0156$

"odds ratio" = indeterminado

Intervalo de $95 \%$ de confiança do "odds ratio" =

$=[0,98 ; \infty]$
Tabela 2) com AVE. Observa-se que 12 (75\%) dos chagásicos considerados, por esta análise, tiveram infarto e 4 (25\%) hemorragia; dos não chagásicos 5 $(31,3 \%)$ apresentaram infarto e, $11(68,7 \%)$ hemorragia. As diferenças são significativas ao nível de $5 \%$ $(\mathrm{p}=0,0156)$.

Todos os chagásicos com AVE hemorrágico eram portadores de hipertensão arterial sistêmica, comprovada clinicamente e/ou à necrópsia, sendo que em 2 deles havia também ruptura de aneurisma do polígono de Willis. Dos 11 não chagásicos, em 7 a etiologia da hemorragia encefálica foi atribuida à hipertensão arterial, em 3 à ruptura de aneurisma e em 1 caso não se pode estabelecer com segurança a causa do distúrbio.

\section{DISCUSSÃO}

Críticas são feitas ao termo AVE, bem como a outros similares como apoplexia e derrame. Embora imprecisos e, em geral não definidos, têm valor prático e fazem parte do cotidiano da terminologia médica. No presente trabalho indicamos por AVE lesões destrutivas e de extensão significativa do encéfalo devido a distúrbio vascular súbito e consideramos dois tipos dos mesmos: 1 o infarto que resulta da privação de suprimento sangüíneo em uma área encefálica, e 2. a hemorragia conseqüência de ruptura espontânea, não traumática, dos vasos sanguíneos. Dentro deste critério não se enquadram entre as hemorragias os enfartes hemorrágicos.

A análise comparativa da freqüência de AVE, no presente estudo, indica que a tendência, dado o nível de significância descritivo de $100 \%$, de um chagásico ter este distúrbio, independentemente de seu tipo, é 1,56 vezes menor que a de um não chagásico apresentá-lo. Este valor resulta do achado de $55(26,4 \%)$ AVE em 208 não chagásicos e 41 (19,7\%) num mesmo número de chagásicos.

Nussenzweig e cols 10 foram os primeiros a enfatizar a importância dos AVE isquêmicos em 
chagásicos; entretanto não se preocuparam com a freqüência do distúrbio. Estudos posteriores 91113 constaram freqüências de $9,4 \%, 22,6 \%$ e $26,3 \%$, respectivamente. No presente estudo, os diagnosticamos em 19,7\% dos 208 chagásicos selecionados. Vários fatores podem explicar estas diferentes freqüências: 1 . a pequena casuística em alguns trabalhos; 2. a proveniência dos casos, se exclusivamente de Hospitais e/ou de outras fontes (p. ex. Serviços de Verificação de óbitos); 3 . os critérios empregados para diagnóstico de AVE; 4. a eventual ocorrência de diferença geográficas na doença de Chagas ${ }^{12}$, etc.

Diante da alta prevalência de infartos encefálicos em chagásicos deveriamos esperar uma freqüência de AVE, independente do tipo, neste grupo de doentes, maior do que nos não chagásicos, o que parece não suceder. A nosso ver isto se explicaria pelo fato de que os AVE hemorrágicos, ao contrário do que sucede com os isquêmicos, em nosso material, foram muito menos freqüentes em chagásicos do que em não chagásicos. Sendo a hipertensão arterial 410 a principal causa de AVE hemorrágico e considerando-se, como alguns admitem (ver revisão bibliográfica em Guariento5), que a hipotensão arterial é achado comum em chagásicos crônicos, poder-se-ia imputar a este último fato a menor freqüência de hemorragias encefálicas em chagásicos. Entretanto alguns estudos 3815 demonstram não haver diferenças pressóricas significativas entre chagásicos e não chagásicos e outros ${ }^{7}$ relatam alta frequência de hipertensão arterial em chagásicos crônicos.

No presente estudo, os chagásicos que tiveram AVE hemorrágico, eram todos portadores de hipertensão arterial sendo esta, em nosso entender, a causa do acidente pelo menos em dois dos quatro casos. Nos outros além da hipertensão havia também aneurisma cerebral roto, causa freqüente de AVE hemorrági$\mathrm{co}^{4}$. A julgar por nossos presentes achados, com grande probabilidade, a hemorragia encefálica em chagásicos, se deve a outras doenças associadas.

Novas investigações devem ser feitas para confirmar se, realmente na DC, é menos freqüente a hipertensão arterial sistêmica, e se isto contribui, e de que maneira, para a menor freqüência de AVE hemorrágico entre os chagásicos. Finalmente deve-se enfatizar a importância destes estudos para o melhor conhecimento não só da DC como também para a encefalopatia hipertensiva e a própria hipertensão arterial sistêmica, bem como da necessidade de metodologia epidemiológica na seleção, grupamento e interpretação dos achados.

\section{SUMMARY}

The frequency of strokes was studied in chronic chagasic and years ofage, non-chagasic patients, older than 15 coming to necropsy in Uberaba, from 1979 than 1988. The study consisted of paired sex and age matched controls. Two hundred and eight pairs were analysed. Either ischemic or hemorrhagic strokes were found in 41 (19,7\%) of the chagasics and in 55 (26.4\%) of the non-chagasic, a difference not significant at the level of $5 \%$. Twelve (75\%) of the former had infarcts and $4(25 \%)$ had brain hemorrhage; five $(31,3 \%)$ of the non-chagasics had ischemic strokes and 11 $(68,7 \%)$ had hemorrhagic strokes. The differences were significant to the level of $5 \%$. The results indicate a high frequency of ischemic strokes in human Chagas' disease and demonstrate a lesser frequency of hemorrhagic stroke in chagasics when compared with non-chagasics.

Key-words: Chagas' disease. Strokes. Ischemic stroke. Hemorrhagic stroke.

\section{AGRADECIMENTO}

Agradecemos ao Prof. Euclides Ayres Castilho pela assistência no estudo estatístico.

\section{REFERÊNCIAS BIBLIOGRÁFICAS}

1. Andrade ZA, Andrade SG. Patologia In: Brener Z, Andrade Z (ed) Trypanosoma cruzi e Doença de Chagas, 1: edição, Guanabara Koogan, Rio de Janeiro p. 199-248, 1979.

2. Breslow NE, Day NE. Statistical Methods in Cancer Research. International Agency for Research on Cancer. Lyon, 1980.

3. Finkielman S. Cartas al comite de redación. Medicina 41: 506, 1981.

4. Gates PC, Barnett HJM, Silver MD. Cardiogenic Stroke. In: Barnett HJM, Mohr JP, Stein BM, Yatsu FM(ed) Stroke. Pathophysiology, Diagnosis and Manegement, Churchill Livingstone Inc, New York p. 1085-1119, 1986.

5. Guariento ME. Doença de Chagas e Hipertensão Arterial. Tese de Mestrado, Universidade de Campinas, Campinas, 1985.

6. Lopes ER, Chapadeiro E. Tafuri WL, Prata AR. Patologia das Principais Doenças Tropicais no Brasil. Doença de Chagas. In: Lopes ER, Chapadeiro E. Raso P, Tafuri WL (ed) Bogliolo Patologia, 4a edição, Guanabara Koogan, Rio de Janeiro p. 1047-1120, 1987.

7. Medrado-Faria MA, Yasuda MAS, Araujo MJO, Lancarotte I, Catapano EA, Ruiz Neto PP. Formas clinicas da doença de Chagas na Grande São Paulo. Arquivos Brasileiros de Cardiologia 38: 99-109, 1982.

8. Mendivil GT. La presion arterial en jovenes de 18 años de una area endémica para la enfermidad de Chagas. Medicina 38: 741-743, 1986.

9. Neiva AR, Andrade ZA. Embolia cerebral em portadores de miocardite crônica chagásica. O Hospital 61: 373379, 1962.

10. Nussenzveig I. Wajchemberg BL. Macruz R, França Netto AS, Timoner J, Azul LGS. Acidentes vasculares cerebrais embólicos na cardiopatia chagásica crônica. Arquivos de Neuro-Psiquiatria 11: 386-402, 1953.

11. Pitella JEH. Ischemic cerebral changes in the chronic chagasic cardiopathy. Arquivos de Neuro-Psiquiatria 42: 105-115, 1984. 
Lopes ER. Marquez JO, Costa Neto B, Menezes AAC, Chapadeiro E. Associaçäo entre acidentes vasculares encefálicos e doença de Chagas. Revista da Sociedade Brasileira de Medicina Tropical 24: 101-104, abr-jun, 1991

12. Prata A (ed). Reunião sobre diterenças geográticas na Doença de Chagas, Universidade de Brasília, Brasilia, 1975.

13. Queiroz AC. Estudo anatomopatológico do encéfalo na forma crônica da doença de Chagas. Revista de Patologia Tropical 7: 135-145, 1978.

14. Shoene WC. O sistema nervoso. In: Robbins SL, Cotran
RS (ed) Patologia Estrutural e Funcional, 2a edição, Interamericana, Rio de Janeiro p. 1269-1324, 1983.

15. Soato GG, Vichi FL, Ruffino Netto A, Machado RR, Carvalho DS. Prevalência de hipertensão arterial em grupos de pacientes chagásicos e não chagásicos em população de hospital geral. Revista Paulista de Medicina 84: 121-123, 1974. 